\title{
Coordinated Power Management and Control of Standalone PV-Hybrid System with Modified IWO-Based MPPT
}

\author{
Chittaranjan Pradhan, Member IEEE, Manoj Kumar Senapati, Member IEEE, Siva Ganesh Malla, Member IEEE, \\ Paresh Kumar Nayak, Member IEEE and Terje Gjengedal, Senior Member IEEE
}

\begin{abstract}
To augment the photovoltaic (PV) power generation conversion, a Maximum Power Point Tracking (MPPT) technique plays a very significant role. This paper introduces a hybrid MPPT-algorithm integrating of Modified Invasive Weed Optimization (MIWO) and Perturb \& Observe (P\&O) technique under rapid weather change and partial shading scenarios for efficient extraction of the maximum power from the standalone PV-based hybrid system. MIWO handles the initial stages of MPPT followed by the application of the P\&O algorithm at the final stages in view of acquiring rapid global peak (GP) and maximal PV power. The studied microgrid comprises of the $P V$ system, battery, electrolyzer, fuel cell, and load. A coordinated DC-voltage regulation and power management strategy between each subsystem of the hybrid microgrid is implemented to save the battery from undesirable charging/discharging operation. Additionally, with the monitoring of DC-voltage, the DC/DC converter associated between the battery and DC-link plays as an MPPT-circuit of the PV without the requirement of an extra dedicated circuit. Takagi-Sugeno (TS)-fuzzy controller is adopted for suppressing/mitigating the voltage oscillations of the microgrid during the variations in solar irradiance/temperature and power demand. The results clearly exhibit the superior performance of the proposed methodology compared to some of the existing techniques.
\end{abstract}

Keywords - Hybrid Power Generation, Maximum Power Point (MPP), Modified Invasive Weed Optimization, Perturb \& Observe, Photovoltaic System, Voltage Control.

\section{NOMENCLATURE}

$\begin{array}{ll}G & \text { Solar irradiance }\left(\mathrm{W} / \mathrm{m}^{2}\right) \\ H_{2} & \text { Hydrogen in the fuel cell } \\ i_{a b c} & \text { Instantaneous 3- } \phi \text { currents at PCC (A) } \\ I_{b a t} & \text { Measured or actual current of the battery (A) } \\ I_{b a t}^{*} & \text { Reference current of the battery (A) } \\ I_{d c} & \text { DC-link current of the microgrid (A) } \\ I_{e l z} & \text { Output current of the electrolyser (A) } \\ I_{p v} & \text { Output current of the PV panel (A) } \\ I_{s o f} & \text { Measured or actual current of the fuel cell (A) } \\ I_{s o f}^{*} & \text { Reference current of the fuel cell (A) } \\ \text { iter }_{\max } & \text { Maximum no. of generations/iterations in MIWO } \\ S_{\max } & \text { Maximum no. of possible production of weeds }\end{array}$

C. Pradhan, and T. Gjengedal are with the Department of Electrical Engineering, UiT The Arctic University of Norway, Narvik Campus, Norway8514, (Email: chittaranjan.pradhan@uit.no, terje.gjengedal@uit.no).

M. K. Senapati, and P. K. Nayak are with the Department of Electrical Engineering, Indian Institute of Technology (ISM) Dhanbad, Jharkhand, India-826004 (e-mail: miitkgp@gmail.com, paresh@iitism.ac.in).

S. G. Malla is with the CPGC Pvt. Ltd., Vishakapatnam, India, (e-mail: mallasivaganesh@gmail.com).

\author{
$S_{\text {min }} \quad$ Minimum no. of possible production of weeds \\ $\sigma_{i t e r} \quad$ Standard deviation at current generation in MIWO \\ $\sigma_{\text {initial }}$ Initial standard deviation in MIWO algorithm \\ $\sigma_{\text {final }} \quad$ Final standard deviation in MIWO algorithm \\ $X_{\text {best }} \quad$ Best candidate or weed \\ $X_{i}^{j} \quad$ Position of the parent weed \\ $X_{i}^{j+1} \quad$ Update position of the parent weed \\ $G_{\max } \quad$ Global maximum power point \\ $k \quad$ Iteration of the P\&O-based technique \\ $\Delta V \quad$ Step change in voltage of $\mathrm{P} \& \mathrm{O}$-based technique (V) \\ $P_{b} \quad$ Battery power $(\mathrm{kW})$ \\ $P_{e l} \quad$ Electrolyzer power $(\mathrm{kW})$ \\ $P_{f c} \quad$ Fuel cell power $(\mathrm{kW})$ \\ $P_{L} \quad$ Load power $(\mathrm{kW})$ \\ $P_{p v} \quad$ PV power $(\mathrm{kW})$ \\ $Q_{1} \quad$ PWM signal for charging the battery \\ $Q_{2} \quad$ PWM signal for discharging the battery \\ $S_{e} \quad$ PWM signal of the electrolyzer converter \\ $S_{f} \quad$ PWM signal of the fuel cell converter \\ $v_{a b c} \quad$ Instantaneous 3- $\Phi$ voltages at PCC (V) \\ $V_{b} \quad$ Output voltage of the battery system (V) \\ $V_{d c} \quad$ DC-link voltage $(\mathrm{V})$ \\ $V_{d c}^{*} \quad$ Reference DC-link voltage (V) \\ $V_{e} \quad$ Operating voltage of the electrolyzer (V) \\ $V_{e}^{*} \quad$ Nominal operating voltage of the electrolyzer (V) \\ $V_{f} \quad$ Operating voltage of the fuel cell (V) \\ $V_{m p p} \quad$ Voltage at maximum power point (V) \\ $V_{p v} \quad$ Output voltage of the PV panel (V)

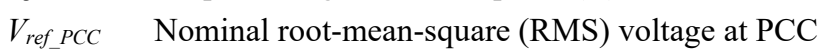

\section{INTRODUCTION}

Tn recent years, there is an increasing trend of electricity generation worldwide using solar photovoltaic (PV) systems due to numerous technical and environmental benefits [1-2]. However, climatic dependency and the high installation cost are the major challenges of presently existing PV power systems. The nonlinear nature of the power-voltage $(\mathrm{P}-\mathrm{V})$ characteristics of a PV system requires a maximum power point tracking (MPPT) technique for maximizing the power conversion efficiency. The maximum power point (MPP) in a $\mathrm{PV}$ power-generation system is a unique point in the $\mathrm{P}-\mathrm{V}$ curve at given solar irradiance and ambient temperature and it varies with environmental experiences such as solar irradiance, temperature, and partial shading, etc. Since these 
parameters vary continuously, tracking the MPP effectively in the PV system is a major challenge. In this perspective, different MPPT techniques are reported in improving the power conversion MPPT-efficiency of the PV system [3-10]. The hill-climbing (HC) method [3], incremental conductance (IC) [4], and perturb and observe (P\&O) [5] are the most popular conventional MPPT techniques. These techniques exhibit good tracking capability under uniform solar irradiance. However, because of slow convergence, the computational burden increases, and the requirement of more sensors make these techniques less attractive. Further, these MPPT techniques are not suitable under varying environmental scenarios (e.g., partial shading conditions (PSCs)) due to the presence of multiple peaks in the power versus voltage $(P-V)$ characteristic curves of the PV [3-4].

In the meantime, with the aim of overcoming the limitations of conventional MPPT techniques, various artificial intelligence MPPT techniques have been proposed by the researches, especially in the highly intermittent environmental conditions [6-15]. These include fuzzy logic control (FLC) [6], Artificial neural network (ANN), Particle swarm optimization (PSO), Firefly algorithm (FA), Ant colony optimization (ACO), Flower pollination algorithm (FPA), Bat algorithm, Jaya algorithm and Grey wolf optimization (GWO), [7-12], etc. However, the abovementioned singly used soft computing techniques have enhanced multi-peak global MPPT capability as compared to the conventional techniques [7, 12-14]. Hence, the researchers have suggested hybrid optimization techniques by integrating two or more algorithms to further upgrade the MPP search process with less computational time. The simulated annealing with PSO (SA-PSO) [7], GWO-FLC [12], PSO-P\&O [13], GWO-P\&O [14], Jaya algorithm with differential evolution (Jaya-DE) [15] and adaptive Neuro-fuzzy inference systemPSO (ANFIS-PSO) [16] are such few examples. The overall performances (i.e., achieve the optimal solution, faster convergence and efficiency) of hybrid soft computing (i.e., a combination of two or more algorithms) based MPPT algorithms are superior over the single soft computing algorithms. However, the convergence speed, the design complexity of the controller parameters, sensor requirements, and the implementation of hardware/microcontroller costs of hybrid MPPT-algorithms are still not attractive. From this perspective, developing/designing a new and hybrid MPPTalgorithm for augmenting the search performance in real-time control problems is always welcome.

Meanwhile, to overcome the intermittent PV power problems and enhance the overall system performance (e.g., efficiency, stability and reliability), standalone PV systems are incorporated with various energy storage devices (e.g., fuel cell, battery, and electrolyzer, etc.) [17-20]. Furthermore, different control strategies are designed to keep the DC-link voltage in the permissible safety limits and ensure an optimum power balance between PV and energy storage devices [1724]. A dynamic power management technique is presented for a standalone hybrid microgrid comprising of solar PV, electrolyzer, fuel cell (FC) and super-capacitor [16]. However, the performance of microgrid is not tested with dump load and unbalanced load conditions. A local hierarchical control strategy for the battery energy storage of a standalone PV- battery system is recommended in [20]. In [21-22], a DC-link voltage control approach for a standalone PV/wind-based system is projected. In [23], an adaptive power management control strategy is highlighted for PV/wind-based DCmicrogrid integration of the energy storage devices (i.e., FC, battery and electrolyzer). A supervisory controller is reported for the operation/power management between wind/PV renewable generation, energy storage, and load power in a hybrid distributed power system [24]. In [20-24], the partial shading condition is not taken into consideration to analyze the performance of the controller. Furthermore, the authors have considered separate DC/DC converters for the solar PV module for MPPT and the charge controller (i.e., charging/discharging operation) in the battery system [20-24].

The aforementioned study clearly shows that there are different hybrid MPPT-algorithms/controllers are available in the literature for standalone PV systems consisting of multiple energy storage devices. However, still, there is a strong need to design/implement a simple and cost-effective controller/MPPT algorithm for standalone PV systems that operate with a wide variety of power system contingencies and environmental effects. Further, an efficient power management control strategy is also very crucial for ensuring a smoothing power balance between PV power, dynamic power demands, and the energy storage devices (i.e., battery, $\mathrm{FC}$, and electrolyzer) of standalone microgrid systems.

To overcome the limitations of the available methodologies, the contributions of this research work are summarized as follows:

- A maiden attempt has been made to introduce an efficient hybrid MIWO-P\&O MPPT algorithm for tracking the maximum power of the PV system. The proposed MPPT algorithm is validated by comparing it to the existing hybrid MPPT strategies based on the PSO-P\&O [13] and GWO-P\&O [14].

- Implementation of a single DC/DC converter (associated between DC-bus and battery energy system (BES)) is employed for regulating the DC-link voltage and MPPT circuit of the proposed standalone PV system. Furthermore, a supervisory DC-link voltage control and power management strategy for the PV-based standalone hybrid system is designed.

- Employment of the TS-fuzzy logic-based robust controller to cater to the voltage stability of the standalone PV power system and its efficacy is equated with the conventional PIcontroller.

- Validation of the proposed controller through OPA-LRT based real-time hardware-in-the-loop (HIL) simulation platform under rapid meteorological changes of solar irradiance/temperature, PSCs, and the change in load.

The results clearly illustrate that the MIWO-P\&O is demonstrated to yield a better search performance to the global maximum power point (GMPP) than PSO-P\&O [13] and GWO-P\&O [14] techniques. As well, it is investigated that the MIWO-P\&O improves the dynamics of the voltage/current and power profiles of the standalone PV system under a wide variety of operating conditions as compared to the techniques reported in [13] and [14]. The rest of this work is organized as follows: First, the configuration and 
modeling of the standalone DC-microgrid are discussed in Section-II. In Section-III, a description of the proposed MIWO-P\&O based MPPT technique is introduced. The control strategy for DC-link voltage regulation with power management between each subsystem (i.e., PV, battery, FC and electrolyzer) of the microgrid is established in Section-IV. In addition, the TS-fuzzy controller is implemented for mitigating the voltage deviations and enhancing power quality of the microgrid during the system contingencies (e.g., variations in solar insolation, change in load, etc.). The results and discussions are exemplified in Section-V for the validation of the proposed framework. At last, the conclusion of the proposed work is presented in Section-V based on the investigation.

\section{The System CONFIGURATION AND MODELING OF THE STANDALONE POWER SYSTEM}

The configuration of the proposed standalone PV-based microgrid system is provided in Fig. 1. The presented standalone system consists of PV modules, battery, electrolyzer (i.e., dump load) and FC. These subsystems/components are connected with the point-ofcommon-coupling (PCC) through a pulse width modulation (PWM)-based inverter controller for supplying power to both 1- $\Phi$ and 3- $\Phi$ loads. The battery energy system (BES) is coupled to DC-link via a bidirectional Buck-Boost DC/DC converter. The operating voltage $\left(V_{b}\right)$ of $\mathrm{BES}$ is $300 \mathrm{~V}$. Similarly, the FC is interfaced to the DC-link through a Boost converter. The operating voltage $\left(V_{f}\right)$ of $\mathrm{FC}$ is $300 \mathrm{~V}$. The electrolyzer is connected to the DC-link via DC/DC Buck converter as it requires a higher current for the generation of hydrogen. The operating voltage $\left(V_{e}\right)$ of the electrolyzer is $86 \mathrm{~V}$. The DC/DC converters operate according to the nominal values of the DC-link voltage $\left(\left(V_{d c}\right)\right.$ through their respective controllers. The details of the proposed control strategies are discussed in Sections-III and IV.

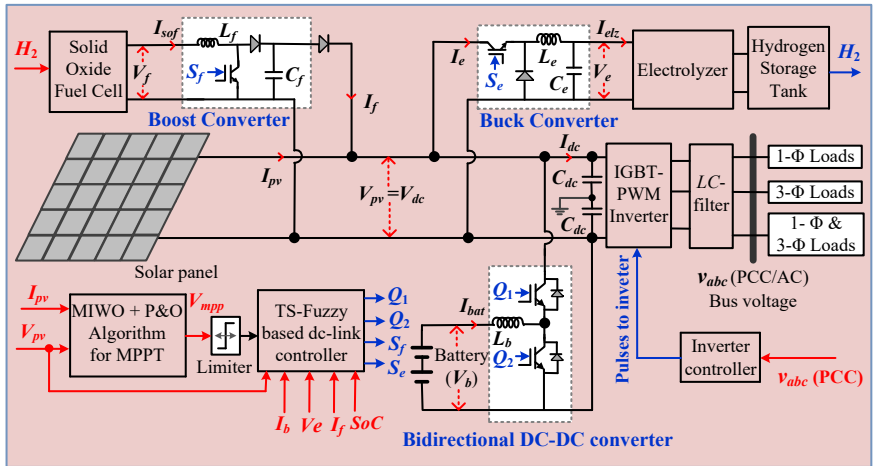

Fig. 1: Schematic of the studied standalone PV-based microgrid system

In this study, a single-diode model of the PV cell is developed for modeling the PV system as depicted in Fig. 2(a). The PV cell is designated as a current-source in parallel with a diode [23-25]. In Fig. 2(a), $I_{p h}$ is the cell's photocurrent (it depends on the solar irradiance and temperature), $D$ is the anti-parallel diode, $I_{D}$ is the diode current of the PV array, $G$ is the solar irradiance. $V_{p v}$ and $I_{p v}$ are the PV voltage and current, respectively. $R_{s h}$ and $R_{s}$ are the intrinsic shunt and series resistances of the array, respectively.

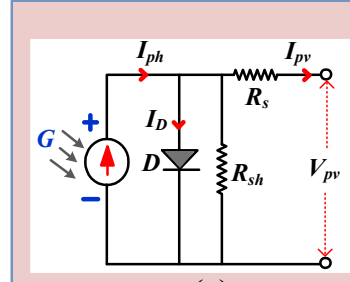

(a)

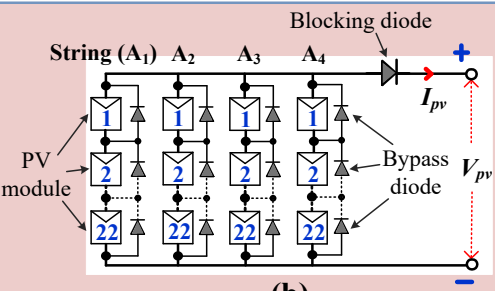

(b)
Fig. 2: (a). Equivalent diagram of PV cell, (b). Configuration of the PV array system

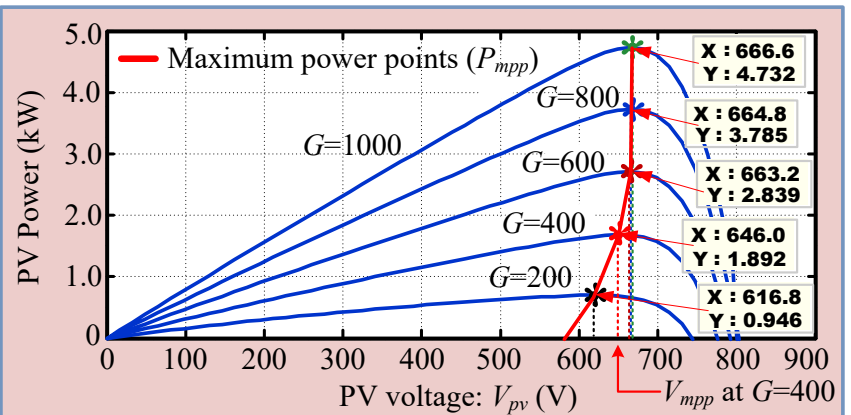

(a)

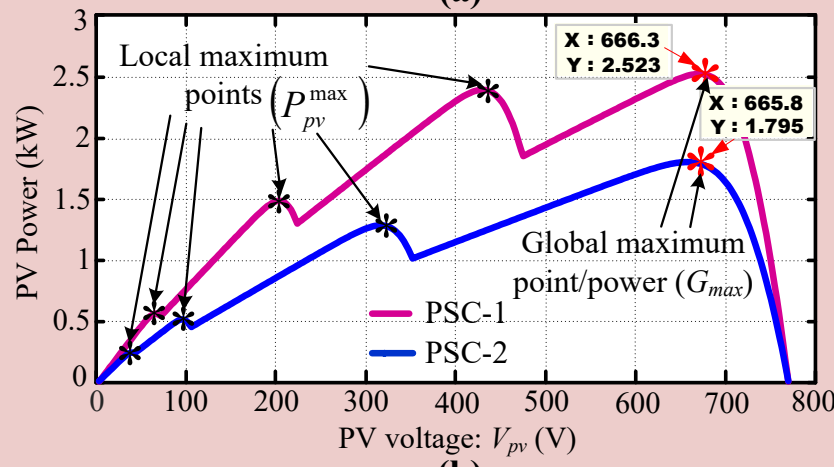

(b)

Fig. 3: $P-V$ characteristics of the PV system for one string:

(a). Variation of solar irradiance, and (b). Under partial shading

In this study, the PV system/array consists of 4-parallel strings (i.e., $\mathrm{A}_{1}, \mathrm{~A}_{2}, \mathrm{~A}_{3}$, and $\mathrm{A}_{4}$ ) and each string is assembled with 22-series connected modules as presented in Fig. 2(b). The nonlinear power versus voltage $(P-V)$ characteristic curve of the PV cells in one string (i.e., 22-series connected PV modules) for symmetrical solar irradiance (Fig. 3(a)) and partial shading (Fig. 3(b)) are displayed, respectively. For analysis, 5-symmetrical solar irradiance conditions (Fig. 3(a)) and 2-partial shaded conditions (Fig. 3(b)) are simulated for one PV-string as specified in Table-1. Furthermore, the modeling of the battery, FC, and electrolyzer is established with the help of the refs. [23-24]. An electrochemical model of Solid Oxide Fuel Cell (SOFC) is established by using a voltage-controlled source, in this study [23-24]. An empirical temperature-dependent voltage-current source/relationship is used to design the electrode kinetics of the electrolyzer cell [23-24]. The electrochemical model of lead-acid battery is realized using a voltage-controlled source with constant resistance [26-27]. Due to the page constraints, the detailed modeling and the data/parameters of the PV, battery, FC, and electrolyzer are not presented in this paper. The design inductors $(L)$ and capacitors $(C)$ value of the microgrid (i.e., Fig. 1) converters/inverter are presented in the Appendix. 
Table 1: Configuration of symmetrical solar irradiance and partial shading patterns in the PV array/system (Fig. 2(b))

\begin{tabular}{|c|c|}
\hline Pattern & For one PV string $\left(\mathbf{A}_{1}-A_{4}\right)$ \\
\hline 1 & $\begin{array}{l}\text { [Symmetrical solar irradiance]: Fig. 3(a) } \\
\text { Modules: } 1-22=200-1000 \mathrm{~W} / \mathrm{m}^{2}\end{array}$ \\
\hline 2 & $\begin{array}{l}\text { [Partial shaded condition-1]: Fig. 3(b) } \\
\text { Modules: } 1-3=1000 \mathrm{~W} / \mathrm{m}^{2} \text {, modules: } 4-8=800 \mathrm{~W} / \mathrm{m}^{2} \text {, } \\
\text { modules: } 9-18=600 \mathrm{~W} / \mathrm{m}^{2} \text {, modules: } 19-22=400 \mathrm{~W} / \mathrm{m}^{2}\end{array}$ \\
\hline 3 & $\begin{array}{l}\text { [Partial shaded condition-2]: Fig. 3(b) } \\
\text { Module: } \quad 1=1000 \mathrm{~W} / \mathrm{m}^{2}, \quad \text { modules: } \quad 2-4=800 \mathrm{~W} / \mathrm{m}^{2} \text {, } \\
\text { modules: } 5-12=600 \mathrm{~W} / \mathrm{m}^{2} \text {, modules: } 13-22=400 \mathrm{~W} / \mathrm{m}^{2}\end{array}$ \\
\hline
\end{tabular}

\section{PROPOSED MIWO-P\&O BASED MPPT TECHNIQUE}

In the traditional perturb and observe (P\&O)-based maximum power point tracking (MPPT) technique, two successive samples of the power levels of the $P-V$ curve are compared by perturbing the nominal voltage $\left(V_{m p p}\right)$ in an erratic direction. The direction of the perturbation is governed by the sign of the power variation for MPPT in the $P-V$ curve. The corresponding voltage to the maximum power point (MPP) is expressed as follows [28-29]:

$$
V_{\text {mpp }}(k)=V_{\text {mpp }}(k-1)+\Delta V \times \operatorname{sign}\left(\frac{d P_{p v}}{d V_{p v}}\right)
$$

where, $\Delta V$ and $k$ are the step voltage change and the number of iterations of the $\mathrm{P} \& \mathrm{O}$-based technique, respectively. It is revealed that the $\mathrm{P} \& \mathrm{O}-$ based technique exhibits a better tracking competency with faster convergence under uniform solar insolation (i.e., solar irradiance) in the presence of a single peak as shown in Fig. 3(a) [4, 28-29]. On the other hand, there are multiple peaks in which the highest point is denoted as the global maximum power point (GMPP) and all other points are local peaks during PSCs as shown in Fig. 3(b). The conventional MPPT techniques, which assume a single peak power point on the PV characteristic curve, cannot guarantee convergence to GMPP; rather these methods mostly get trapped into one of the local peaks due to their inability to differentiate between the local and global peaks. In such situations, the conventional $\mathrm{P} \& \mathrm{O}$ algorithm fails to follow the $V_{m p p}$ corresponding to the global MPP $\left(G_{\max }\right)$ [1315]. To augment the GMPP searching ability (i.e., attain the optimal value and faster convergence with less oscillation) of the PV system under PSCs, the modified invasive weed optimization (MIWO) algorithm is integrated with the $\mathrm{P} \& \mathrm{O}$ technique, in this work. The location and magnitude of local and global MPPs are influenced stochastically by varying shading pattern and the configurations of the PV array. Fig. 3(b) clearly shows the presence of multiple power peaks with one GMPP during PSCs and the magnitude/position of the MPP varies with change the in shading pattern of the PV.

Invasive Weed Optimization (IWO) is a simple and effective numerical stochastic optimization algorithm inspired by colonizing weeds [30]. It is demonstrated that the IWO has high capability in searching the global maxima/minima as compared to the existing recent evolutionary-based algorithms and has a better adoption nature of the changing environmental conditions [30]. Firstly, initialize the randomly generated parent weeds/population in a search space.
Secondly, each weed grows and produces its child weed. The generation of the number of child weeds of each plant depends on its fitness value or ranking. It is distributed from the maximum possible $\left(S_{\max }\right)$ production to its minimum weeds $\left(S_{\min }\right)$ according to the Cauchy distribution function (CDF) of random variables. In this work, the value of $S_{\max }$ and $S_{\min }$ is chosen as 5 and 1, respectively. Normally, the Gaussian distribution function (GDF) is employed in IWO algorithm to update the weeds position in the search space. However, CDF function can contribute to superior results in place of GDF for producing a better optimal solution with faster convergence performance [30]. The Cauchy density function has mainly two parameters such as location and scale parameters. The standard deviation is nothing but the scale parameters. The MIWO has the ability to deal with the high dimension test functions that help in solving complex search problems with faster convergence towards the optimal solution. The newly generated child weeds are normally distributed over the search space with mean of the parent weed position and the varying standard deviation which is presented as follows [30]:

$\sigma_{\text {iter }}=\frac{\left(\text { iter }_{\max }-i t e r\right)^{n}}{\text { iter }_{\max }^{n}}\left(\sigma_{\text {initial }}-\sigma_{\text {final }}\right)+\sigma_{\text {final }}$

where, iter and iter $_{\max }$ represent the current (i.e., present) generation/iteration and the maximum no. of generations, respectively. $\sigma_{\text {iter }}, \sigma_{\text {initial }}$ and $\sigma_{\text {final }}$ stand for the standard deviation at the current generation, the initial standard deviation and the final standard deviations, respectively. $n$ is the nonlinear modulation index. In this study, the value of iter $_{\text {max }}, \sigma_{\text {initial }}, \sigma_{\text {final }}$ and $n$ are selected as 100, 10e-6, 0.7 and 3, respectively.

In MIWO algorithm, maximum weeds $\left(W_{\max }\right)$ are generated around the parent weeds. In this study, the value of $W_{\max }$ is chosen as 15. The best weed can be used to move the remaining weeds to the best position. The position of each weed gets updated in such a way that all weeds slowly and steadily gravitate towards the global maximum point in the search space. The updated value of the weed position (i.e., PV voltage) can be obtained by using the previous position and the difference between previous position and the best position is as follows:

$X_{i}^{j+1}=X_{i}^{j}+m \sigma_{\text {iter }} \times$ Cauchy $(0,1) \times\left(X_{\text {best }}-X_{i}^{j}\right) ; \quad i=1,2 \ldots \ldots, W_{\max }$

$$
\text { with } \quad m=\Delta V \times \operatorname{sign}\left(\frac{d P_{p v}^{\max }}{d V_{\text {mpp }}}\right)
$$

where, $X_{i}{ }^{j}$ is the $i^{\text {th }}$ weed position at $j^{\text {th }}$ iteration. $X_{i}{ }^{j+1}$ is the update/new weed position at $j^{\text {th }}$ iteration, $X_{\text {best }}$ is the best weed found in the whole population. The value of $\Delta V$ is considered as $0.06 \mathrm{~V}$. It is examined that MIWO improves search performance because the Cauchy distribution function and standard deviation maintain better population-diversity characteristic in the search space [30].

While performing MPPT by employing MIWO technique, it takes more time for all the weeds to reach on a global maximum power point and hence in order to minimize the search process, the majority of the weeds (i.e., particles) when reaching mutually closer to each other, the $\mathrm{P} \& \mathrm{O}$ algorithm is instigated with its starting point as the position of the best weed in the MIWO algorithm. The P\&O method is a promising algorithm which converges to GMPP if the starting 
point of the search is nearer to the GMPP. Hence, it is recommended to examine the $P-V$ curve initially with MIWO and then execute the $\mathrm{P} \& \mathrm{O}$ method starting with the position of the best weed of MIWO. Thus, the MIWO supported P\&O (MIWO-P\&O) technique can provide enhanced performance in the terms of GMPP $\left(G_{\max }\right)$ with less oscillation under varying environmental conditions. The flow chart of the MIWO-P\&O based hybrid MPPT-algorithm is exhibited in Fig. 4. In Fig. 4, ' $\varepsilon$ ' is a tolerance factor, which value is 0.005 . The efficacy of the MIWO-P\&O algorithm over the PSO$\mathrm{P} \& \mathrm{O}[13]$ and GWO-P\&O [14] is presented in Section-V.

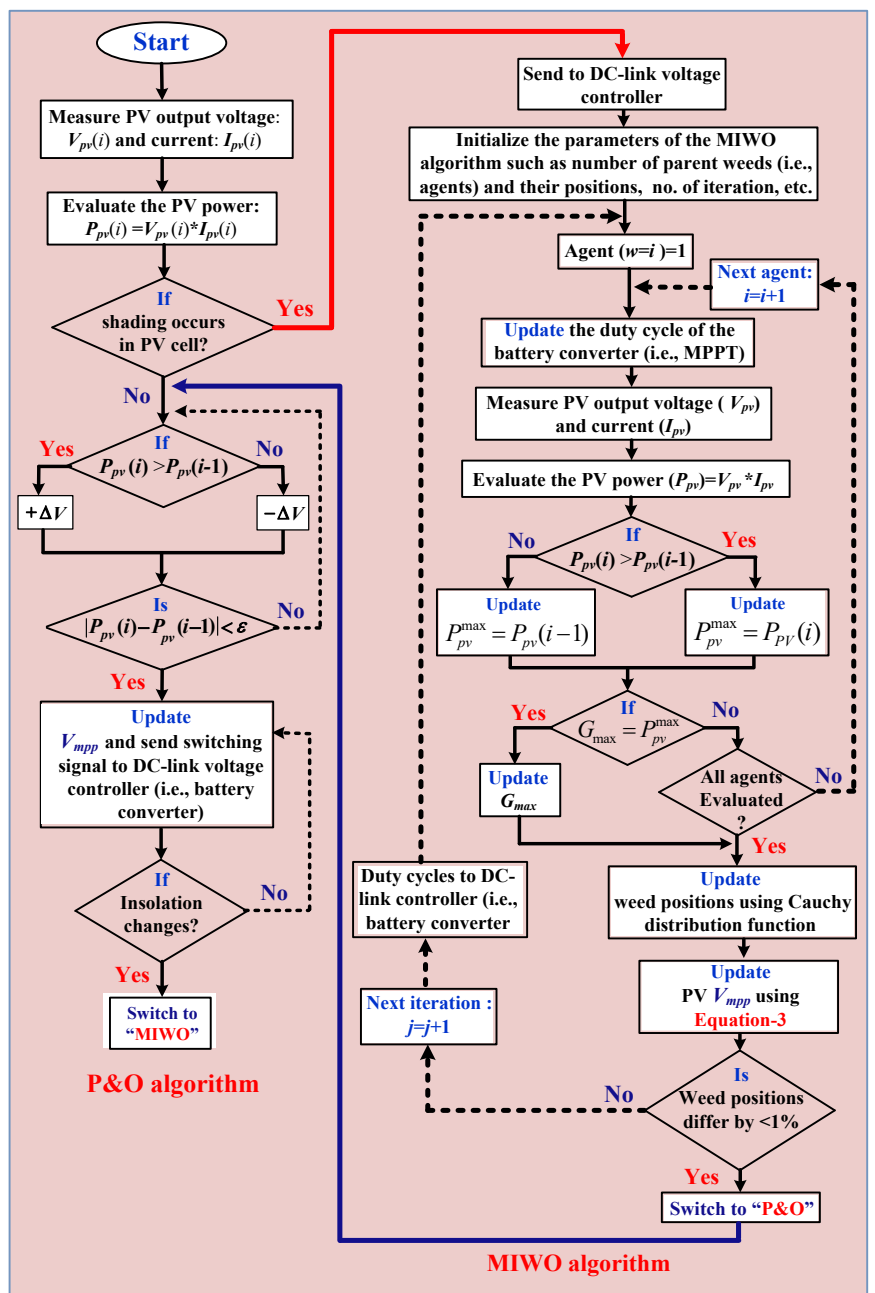

Fig. 4: Flow chart of proposed MIWO-P\&O based MPPT control scheme

\section{THE CONTROL StRATEGIES EMPlOYED FOR THE STANDALONE PV SYSTEM}

\subsection{Proposed coordinative DC-link voltage control}

The power mismatch between generation and load causes the change in the actual DC-link voltage $\left(V_{d c}\right)$. In order to synchronize the $V_{d c}$ at its reference value, a cooperation control methodology is needed among PV, load and energy storage devices such as the BES, FC and an electrolyzer (i.e., dump load). The control structures of the $\mathrm{DC} / \mathrm{DC}$ converters used for the BES, electrolyzer and fuel cell which keeps the DC-link voltage within the permissible range is presented in Fig. 1 and Fig. 5. In order to enhance the life span of BES, the state of charge (SoC) of the battery is restricted between 0.2 and 0.8 , in this study. The upper and lower limits and the current status of battery SoC are compared to determine the ON/OFF switching control action of the BES, FC and electrolyzer. In this work, the PV panel is directly coupled to the DC-bus and MIWO assisted P\&O algorithm (Fig. 1) is incorporated for MPPT using $\mathrm{DC} / \mathrm{DC}$ converter (operated between the BES and DC-link). The DC/DC converter not only regulates the DC-link voltage, but also performs MPPT, and hence a supplementary MPPT circuit is not needed for the $\mathrm{PV}$. The MPPT voltage $\left(V_{m p p}\right)$ is taken as the reference (i.e., nominal) value of the DC-link voltage on the controller of the converter in order to operate the PV at MPP.

In this study, the BES voltage is kept lower as equated to reference DC-link voltage $\left(V_{d c}^{*}\right)$ and consequently, a less number of batteries are required to be interconnected in series for getting the desired voltage level. In the suggested system, BES terminal voltage is kept at about $300 \mathrm{~V}$ while $V_{d c}^{*}=V_{m p p}$ (signal delivered by the MIWO assisted $\mathrm{P} \& \mathrm{O}$ algorithm) is the output voltage of the BES converter (i.e., reference DC-link voltage). Allowing for the voltage drop across the $L C$-filter (associated after inverter), the required minimum DC-link voltage is $640 \mathrm{~V}$ to maintain the output PCC voltage at $400 \mathrm{~V}$ RMS (i.e., the line-line voltage). A limiter is incorporated after the $V_{m p p}$ signal by the proposed algorithm (as shown in Fig. 1) which constrains the reference voltage of the DC-link between $640 \mathrm{~V}$ to $700 \mathrm{~V}$ of the DC/DC converter control. For the highest possible irradiance (i.e., $1000 \mathrm{~W} / \mathrm{m}^{2}$ ), the corresponding $V_{m p p}$ is $666.6 \mathrm{~V}$ (shown in Fig. 3(a)) which is lower than the maximum DC-link voltage safety limit (i.e., $700 \mathrm{~V})$. The minimum threshold limit of DC voltage is $640 \mathrm{~V}$ which corresponds to $300 \mathrm{~W} / \mathrm{m}^{2}$ irradiance. The proposed algorithm/ controller acts as a constant voltage MPPT algorithm for irradiance less than $300 \mathrm{~W} / \mathrm{m}^{2}$, or during the night time and under non-sunny days. Under such circumstances, the limiter keeps the reference voltage of the DC-bus at a minimum level of $640 \mathrm{~V}$.

As per the IEEE-1547 and EN-50160 standard limits, the maximum allowable deviations in DC-link voltage $\left(V_{d c}\right)$ and PCC voltage should be less than $\pm 10 \%$ (i.e., \pm 0.1 p.u.) by virtue of the protection of DC-bus and power electronics devices that are coupled/interconnected to the microgrid [31$33]$. Hence, in this paper, the maximum $\pm 10 \%$ deviation in $V_{d c}$ (i.e., $600 \mathrm{~V}$ to $720 \mathrm{~V}$ ) is considered while designing the controller. Moreover, for secure and stable power system operation, the protection circuit/scheme will be activated during the severe contingencies (e.g., fault and large change in load) when $V_{d c}$ goes beyond its safety limits [17-18].

The actual DC-link voltage $\left(V_{d c}\right)$ is equated with the nominal voltage $\left(V_{d c}^{*}=V_{m p p}\right)$ and the error signal is fed to the TS-fuzzy controller for the BES controller as shown in Fig. 5. Its output is considered as the nominal current for the BES which is compared with the actual BES current $\left(I_{b a t}\right)$ for generating the PWM signal. A hysteresis band approach is designed to switch either $Q_{1}$ or $Q_{2}$ of the DC/DC converter. The charging of the battery is controlled by $Q_{1}$. Whenever the SoC reaches its upper threshold limit (i.e., the SoC is more than 0.8 and the battery is fully charged), then the electrolyzer receives the surplus/excess power from the PV system as the load power is less than the power generation. The controller is designed to stop the pulses to $Q_{1}$ (i.e., BES won't receive the power) and the surplus power will be consumed by the 
electrolyzer through the switch $S_{e}$. In order to control the DClink voltage, $Q_{1}$ signal is integrated with the electrolyzer controller. Hence, the Buck converter controller can operate the output voltage of the electrolyzer $\left(V_{e}\right)$ as well as the DClink voltage at their nominal values during the production of hydrogen. During that period, the BES maintains the DC-link voltage through $Q_{2}$. However, in the case of light load and maximum PV power, whenever the surplus power is more than electrolyzer power rating, the deloading operation of the PV system can be implemented for power balancing [23].

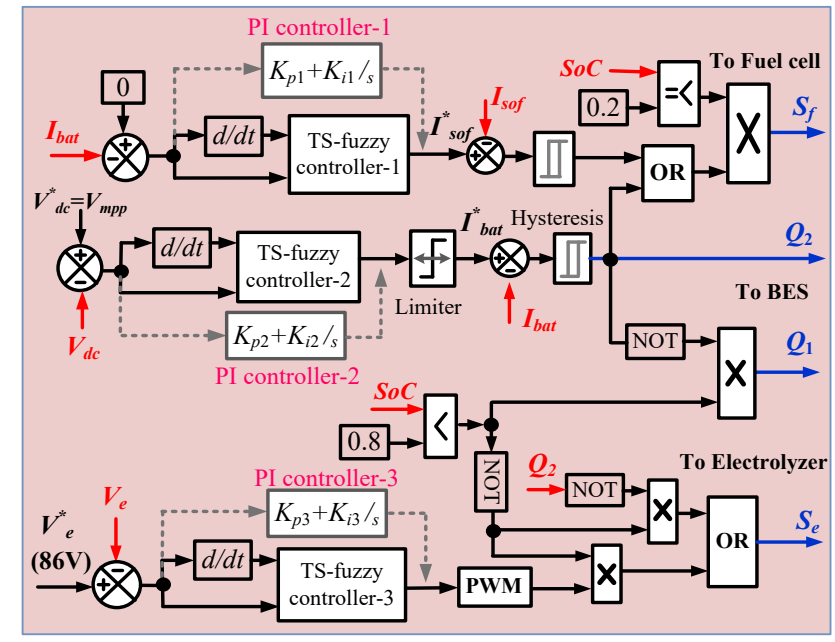

Fig. 5: Schematic of the proposed DC-link voltage controller

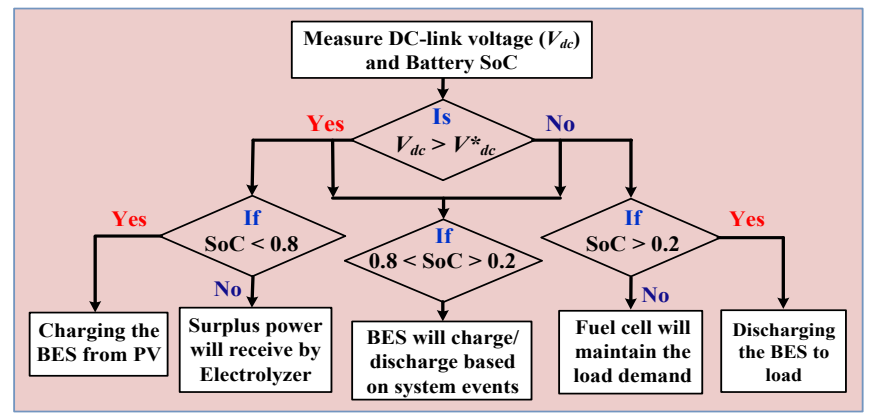

Fig. 6: Flowchart of the coordinative power management algorithm

Furthermore, whenever the SoC of BES is less than 0.2 (i.e., battery is fully discharged as $\mathrm{SoC}$ is below the lower threshold limit of 0.2 and the current flowing through it decreases), then FC will be switched ON $\left(S_{f}\right)$. It indicates that the load power is more than power generation and BES is unable to supply power. At this time, BES is switched OFF for increasing the lifespan of the battery. So, the reference current of the BES is set zero (i.e., SoC is less than 0.2) as denoted in Fig. 5. The FC regulates the DC-link voltage at its nominal value so that the battery current $\left(I_{b a t}\right)$ is maintained zero during this period. Hence, no power is supplied by the BES as the FC meets the load demand. Similarly, according to the system events (e.g., variations in load power and PV power, etc.) when the SoC of the battery lies between 0.2 to 0.8 , the BES will charge/discharge through the bi-directional DC/DC converter for a coordinated DC voltage regulation and power management. The flow chart of the above-discussed coordinating power management between PV, BES and electrolyzer is illustrated in Fig. 6. Additionally, the TS-fuzzy control technique is employed for mitigating the transient/dynamic responses of the DC-link voltage (Fig. 5) and PCC/inverter voltage (Fig. 7) during the system events.

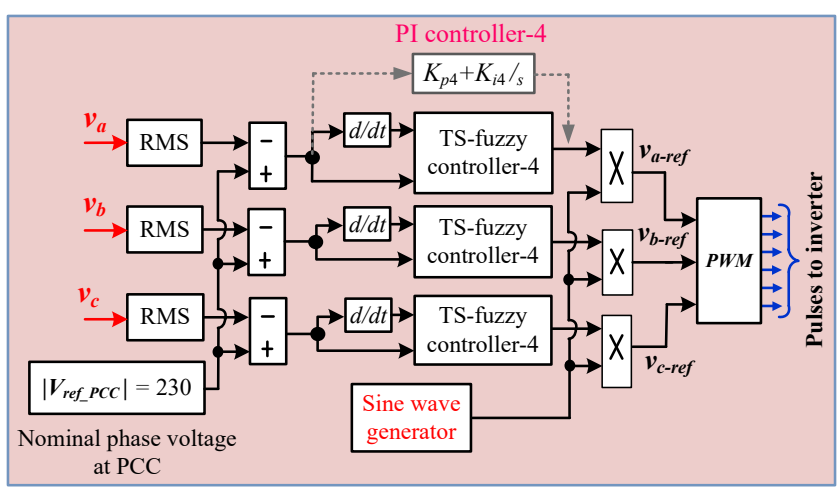

Fig. 7: TS-fuzzy based inverter controller

\subsection{TS-fuzzy logic control}

Since the linguistic rule consequent of TS-fuzzy has become variable by means of its parameters with an infinite number of gain variation characteristics, it can deal with the complex control problems effectively. Consequently, it supervises the system uncertainties and upgrades the stability of the power system effectively during the meteorological changes and load variations [34-35]. On the other hand, it is examined that the TS-fuzzy controller can contribute a better control solution than PI-controller under nonlinear control problems and system uncertainties for varying operating conditions [34-35]. Thus, with the purpose of enhancing the system dynamic performance, the TS-fuzzy based controller is employed in this study.

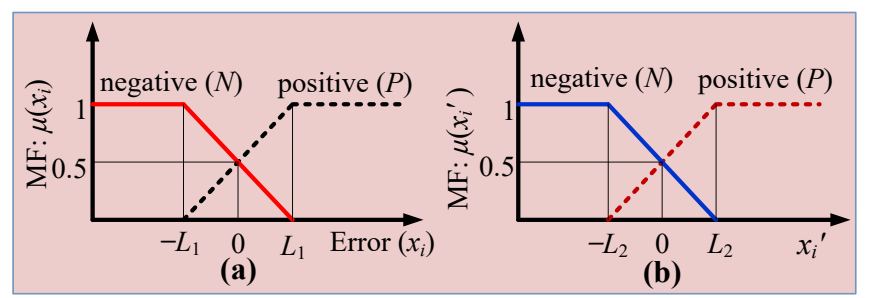

Fig. 8: Fuzzy membership functions for: (a). Voltage/current error signal $\left(x_{i}\right)$, and (b). Derivative of the voltage/current error signal $\left(x_{i}^{\prime}\right)$

The deviations in voltage/current error $\left(x_{i}\right)$ and it's derivative $\left(x_{i}^{\prime}\right)$ signal are taken as the input variables to the fuzzy control, for designing the TS-fuzzy controller (in Figs. 5 and 7). The input voltage/current error and its derivative signals are fuzzified by means of two linguistic memberships (MFs) values; $P$ and $N$ for positive and negative, respectively as described in Fig. 8. The MFs of the two input linguist variables; $P$ and $N$ for $x_{i}$ and $x_{i}{ }^{\prime}$ signals are expressed as (4) and (5), respectively.

$\mu_{P}\left(x_{i}\right)=\left\{\begin{array}{ll}0, & x_{i}<-L_{1} \\ \frac{x_{i}+L_{1}}{2 L_{1}}, & -L_{1} \leq x_{i} \leq L_{1} \\ 1, & x_{i}>L_{1}\end{array}\right.$ and $\mu_{N}\left(x_{i}\right)= \begin{cases}1, & x_{i}<-L_{1} \\ \frac{-x_{i}+L_{1}}{2 L_{1}}, & -L_{1} \leq x_{i} \leq L_{1} \\ 0, & x_{i}>L_{1}\end{cases}$
$\mu_{P}\left(x_{i}^{\prime}\right)=\left\{\begin{array}{ll}0, & x_{i}^{\prime}<-L_{2} \\ \frac{x_{i}^{\prime}+L_{2}}{2 L_{2}}, & -L_{2} \leq x_{i}^{\prime} \leq L_{2} \\ 1, & x_{i}^{\prime}>L_{2}\end{array}\right.$ and $\mu_{N}\left(x_{i}^{\prime}\right)= \begin{cases}1, & x_{i}^{\prime}<-L_{2} \\ \frac{-x_{i}^{\prime}+L_{2}}{2 L_{2}}, & -L_{2} \leq x_{i}^{\prime} \leq L_{2} \\ 0, & x_{i}^{\prime}>L_{2}\end{cases}$ 
The TS-fuzzy controller is represented by the following simplified four fuzzy rules:

Rule-1: If $x_{i}(\kappa)$ is $N$ and $x_{i}^{\prime}(\kappa)$ is $N$, then $Z_{1}=a_{1} x_{i}(\kappa)+a_{2} x_{i}^{\prime}(\kappa)$.

Rule-2: If $x_{i}(\kappa)$ is $N$ and $x_{i}^{\prime}(\kappa)$ is $P$, then $Z_{2}=a_{3} Z_{1}$.

Rule-3: If $x_{i}(\kappa)$ is $P$ and $x_{i}^{\prime}(\kappa)$ is $N$, then $Z_{3}=a_{4} Z_{1}$.

Rule-4: If $x_{i}(\kappa)$ is $P$ and $x_{i}^{\prime}(\kappa)$ is $P$, then $Z_{4}=a_{5} Z_{1}$.

In the above rules, $Z_{1}, Z_{2}, Z_{3}$ and $Z_{4}$ represent the consequent of the TS-fuzzy controller, $k$ is the $k^{\text {th }}$ sampling instant. $a_{1}, a_{2}, a_{3}, a_{4}$ and $a_{5}$ are the fuzzy constants. The value of the fuzzy constants is listed in the Appendix. Moreover, the corresponding proportional $\left(K_{p}\right)$ and integral $\left(K_{i}\right)$ parameter of the PI-controller is reported in the Appendix. Based on the integral-square-error (ISE) performance criteria, the coefficients of the PI-controllers are designed [35].

The output of the TS-fuzzy controller $(Y)$ is obtained by using the generalized defuzzifier, which is evaluated as follows:

$Y=\frac{\left(F_{1} \times Z_{1}+F_{2} \times Z_{2}+F_{3} \times Z_{3}+F_{4} \times Z_{4}\right)}{\left(Z_{1}+Z_{2}+Z_{3}+Z_{4}\right)}$

where, $F_{1}=\min .\left\{\mu_{P}\left(x_{i}\right), \mu_{P}\left(x_{i}^{\prime}\right)\right\}, F_{2}=\min .\left\{\mu_{P}\left(x_{i}\right), \mu_{N}\left(x_{i}^{\prime}\right)\right\}$ $F_{3}=\min .\left\{\mu_{N}\left(x_{i}\right), \mu_{P}\left(x_{i}^{\prime}\right)\right\}, F_{4}=\min .\left\{\mu_{N}\left(x_{i}\right), \mu_{N}\left(x_{i}^{\prime}\right)\right\}$

As the value of ' $Y$ ' is adapted dynamically using the fuzzybased controller, which results in improving the stability of the power system during system events/contingencies.

\subsection{Unbalanced PCC voltage compensation topology}

In practice, power systems unbalance in nature due to the presence of unbalance switching operation in each phase and faults (i.e., the current in each phase is not the same due to unbalanced load) of a power system. The presence of unbalanced loads has an unsustainable impact on power system voltage stability performance. Owing to, the unbalanced voltage drops across the $L C$-filter which results in making the PCC voltage unbalanced. The voltage unbalance factor (i.e., the ratio of negative sequence to the positive sequence of fundamental voltage component) may not be within the permissible limit (i.e., less than $1 \%$ ) in each phase of the PCC during the unbalanced switching operation. So as to maintain a balanced phase voltage and mitigate load variations issues of the $3-\Phi$ power system, an appropriate inverter controller technique is required to control individual phase voltages. To achieve this goal, three individual TSfuzzy controllers are used for each phase. Hence, the PMWbased modulation indexes (MI) signals can generate/regulate for each phase independently as shown in Fig. 7. As a result, three different MI signals can generate under the unbalanced load conditions to maintain the PCC voltage balanced. However, in the case of balanced load conditions, equal MIs will be generated for each phase through the PWM-based inverter controller. So, the presented controller maintains a stable and balanced 3- $\Phi$ supply at the load-bus under both balanced and unbalanced load scenarios. The error signal and the derivative of the error signal between the actual RMS phase voltage and the nominal PCC voltage (i.e., 230V) are taken as the input signals to the TS-fuzzy controller as presented in Fig. 7.

\subsection{Unit sizing of the standalone hybrid power system}

Optimization of unit sizing is important in a renewablebased hybrid power generation system as it helps to minimize the operating and generation cost as well as maintain the power system stability and reliability. In this paper, based on the load profile of the Pacific Northwest area, the sizing/installed capacity of the PV and energy storage systems such as the BES, FC and electrolyzer of the microgrid is designed [23]. For analysis, the hourly load profile of the Pacific Northwest area (PNA) is considered, where the peak power demand $\left(P_{L, \max }\right)$ and minimum demand $\left(P_{L, \text { min }}\right)$ is $14.6 \mathrm{~kW}$ and $5.85 \mathrm{~kW}$, respectively [23].

The installed PV module capacity is considered as $20-30 \%$ more of peak load [19]. So, the estimated installation PV capacity is $18.9 \mathrm{~kW}$ (almost $30 \%$ more than the peak load of the PNA). Hence, four PV strings are connected in parallel to generate the net power of $18.92 \mathrm{~kW}$ as shown in Fig. 2(b), where the installed capacity of 22-series connected PV cells in a single row are $4.732 \mathrm{~kW}$. In order to decide the capacity of the battery bank, the depth of discharge $(D o D)$ of the battery is considered as $60 \%$ [23]. This is decided that even when the PV power is zero, it should cater to the energy requirement of $15 \mathrm{~kW}$ load for approximately an hour. The installed capacity of the batter energy system is evaluated as follows:

$$
\text { Installed battery capacity }=\frac{15 \mathrm{~kW} \times 1 \mathrm{~h}}{300 \mathrm{~V} \times 0.6}=83.33 \mathrm{Ah}
$$

where, $300 \mathrm{~V}$ is the net output voltage $\left(V_{b}\right)$ of the battery system. Hence, twenty-five numbers of batteries are connected in series with each having $12 \mathrm{~V}$ rating to achieve the required 83.33Ah and $300 \mathrm{~V}$ battery system.

Additionally, when there is no PV power, the FC supplies the necessary power for power balancing at the peak load scenario. Based on the peak load $\left(P_{L, \max }=14.6 \mathrm{~kW}\right)$, the FC capacity is decided [23]. For the best utilization, the rating of FC is taken as $18 \mathrm{~kW}$, which is assumed as $20 \%$ more than the peak load. As far as the dump load (i.e., electrolyzer) is concerned, its rating depends on the maximum availability of the surplus power of the microgrid [23]. Since electrolyzer is very costly, $60 \%$ of the maximum available surplus power from PV power generation is considered in determining the electrolyzer capacity and expressed as follows:

Installed capacity of electrolyzer $=0.6 \mathrm{X}$ (Maximum $\mathrm{PV}$ power generation - Minimum load $)=0.6 \times(18.9-5.85) \mathrm{kW}=7.83 \mathrm{~kW}$.

\section{RESUlTS AND DisCUSSIONS}

To investigate the performance of the proposed control methodology, a PV-based standalone hybrid power system is considered as shown in Fig. 1. In this study, the detailed plant model (Fig. 1) and the controller (Figs. 4-8) are realized on a real-time simulator (RTS) which can closely replicate the dynamics of physical systems and controller. The RTS is a combination of advanced computer hardware and comprehensive software. It has a parallel-processing hardware architecture assembled in modular units. Each unit contains both processing and communication modules. With the aim of implementing the HIL setup, two OPAL-RT (manufactured by OPAL-RT Technologies) units are considered with corresponding computers; one used for modeling of PV base hybrid power system (Fig. 1) and the other one for the controller as exhibited in Fig. 9 [35-36]. The analog signals 
are going from the plant (i.e., OPAL RT-1) to controller (i.e., OPAL RT-2) and digital signals are coming from the controller to the plant. The communication between each OPAL-RT is done in actual analog and digital signals. So, a HIL path is established between both OPAL-RTs for supervising the real-time dynamics of the power system dynamics effectively [36]. The effectiveness of the suggested control approach is verified by considering the following case studies below.

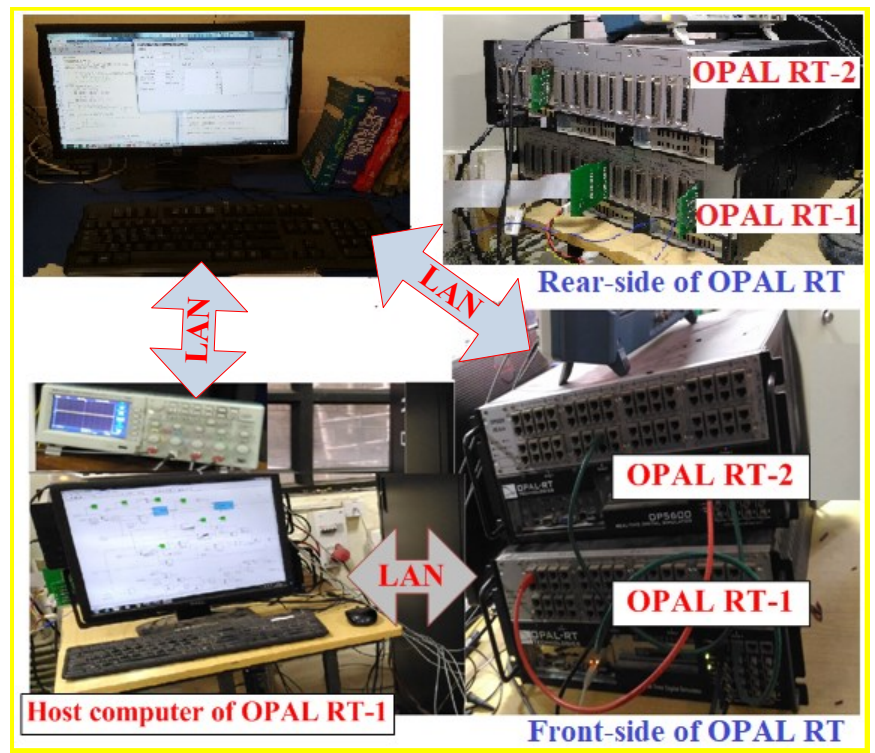

Fig. 9: HIL laboratory setup on OPAL-RT platform

Case A:- Performance evaluation of MPPT under variation of solar insolation (i.e., solar irradiance)

In this case study, the solar insolation is changed from $1000 \mathrm{~W} / \mathrm{m}^{2}$ to $900 \mathrm{~W} / \mathrm{m}^{2}$ at the time $(t)=1.2 \mathrm{~s}$ as signified in Fig. 10(a). A fixed load of $14.6 \mathrm{~kW}$ is considered, in this case. For the above system events, the reference DC-link voltage $\left(V_{d c}^{*}=V_{m p p}\right)$ is plotted in Fig. 10(b) which is derived from the presented MPPT algorithms tracked duly using $V_{m p p}$ as discussed in Sections-II and III. As the solar irradiance decreases after $t=1.2 \mathrm{~s}$, the reference DC voltage decreases on MPPT which are shown in Fig. 3(a) and Fig. 10(b). The hybrid MIWO-P\&O algorithm updates the reference DC-link voltage to operate the PV system at MPP according to the climatological changes of solar irradiance/temperature. The comparative reference DC-link voltage $\left(V_{m p p}\right)$ performance indexes in the terms of maximum voltage deviation $\left(V_{p}\right)$, minimum voltage deviation $\left(V_{d}\right)$, and settling time (i.e., faster convergence) for the above-mentioned MPPT techniques are presented in Table-2. From the results, it can be illustrated that the proposed MIWO-P\&O technique produces a better dynamic MPPT voltage $\left(V_{m p p}\right)$ response with faster converge as compared to the PSO assisted P\&O [13] and Grey wolf assisted $\mathrm{P} \& \mathrm{O}$ [14].

Table 2: Comparative dynamic DC voltage $\left(V_{m p p}\right)$ performance

\begin{tabular}{|l|c|c|c|}
\hline $\begin{array}{c}\text { Performance indexes } \\
\text { Fig. 10(b) }\end{array}$ & $\begin{array}{c}\text { Scheme } \\
{[\mathbf{1 3}]}\end{array}$ & $\begin{array}{c}\text { Scheme } \\
{[\mathbf{1 4}]}\end{array}$ & $\begin{array}{c}\text { Proposed } \\
\text { scheme }\end{array}$ \\
\hline Maximum deviation $\left(V_{p}\right)$ & 1.85 & 1.5 & 0.8 \\
\hline Minimum deviation $\left(V_{d}\right)$ & 3.8 & 3.0 & 2.0 \\
\hline Settling time $\left(t_{s}\right)$ & 0.18 & 0.15 & 0.07 \\
\hline
\end{tabular}

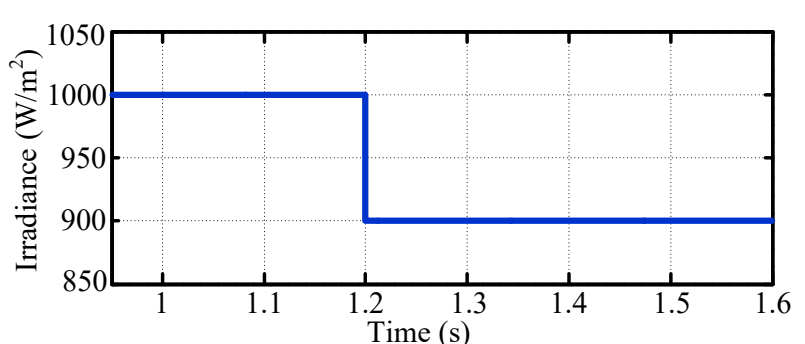

(a)

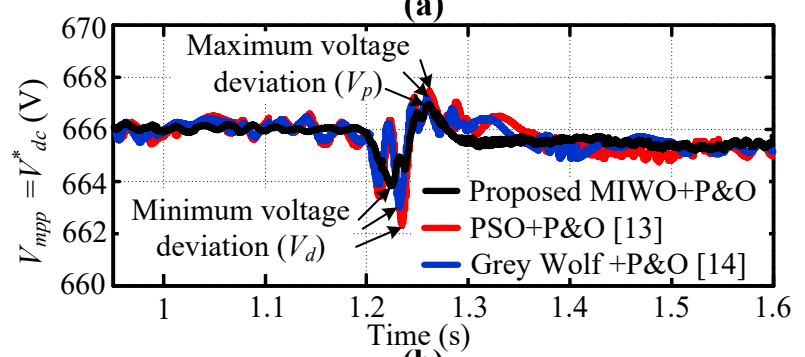

(b)

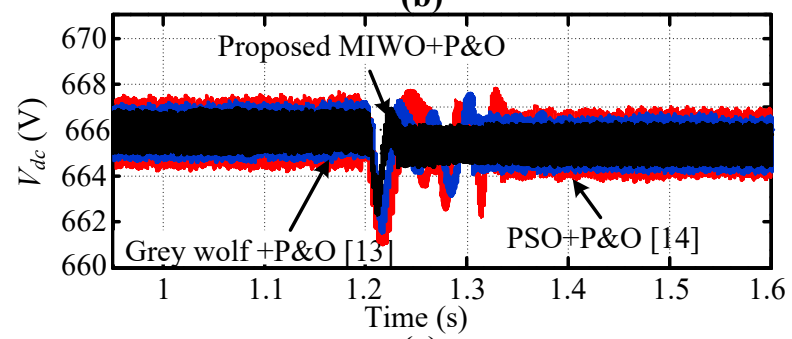

(c)

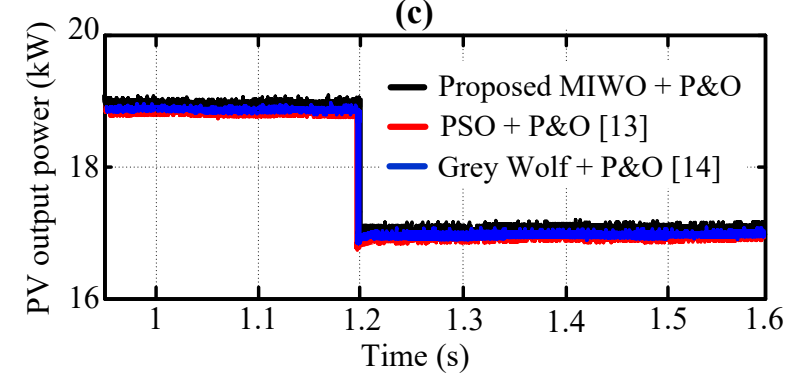

(d)

Fig. 10: (a). Variation in solar irradiance, (b). Reference DC voltage $\left(V_{d c}^{*}=V_{m p p}\right)$, (c). Actual DC-link voltage $\left(V_{d c}\right)$, and (d). Actual PV power

Similarly, the comparative dynamic response of DC-link voltage $\left(V_{d c}\right)$ of the microgrid is shown in Fig. 10(c) from which it can be determined that the performance of the DC voltage controller is satisfactory in both transient as well as steady-state circumstances. The exact values of the percentage of actual DC-link voltage deviations from its nominal value are mentioned in Table-3. In Fig. 10(c), the DC-link voltage is followed by the $V_{m p p}$ which is generated by the presented MPPT algorithms. The $V_{m p p}$ signal is employed as the reference voltage signal to the DC/DC converter (associated between DC-bus and BES) control, as discussed in Sections-II and III. The DC/DC converter helps to regulate the DC-link voltage corresponds to $V_{d c}^{*}=V_{m p p}$ during the system events. As a result, the PV system operates at its MPP because of controlling of the DC-link voltage at $V_{m p p}$. The comparative actual extracted output power $\left(P_{p v, o u t}\right)$ of PV for different MPPT techniques are presented in Fig. 10(d). The efficacy of an MPPT-algorithm is benchmarked using the MPPT efficiency $\left(\eta_{M P P T}\right)$ equation as follows [5]:

$\% \eta_{M P P T}=\frac{P_{p v, o u t}}{P_{M P P T}} \times 100$ 
where, $P_{M P P T}$ represents the maximum (theoretical) achievable power (Fig. 3). $P_{p v \text {,out }}$ is the power extracted from the PV array which depends upon the ability of the MPPT to be as close as possible to true MPP. The higher the accuracy of the MPPT technique higher is the $\eta_{M P P T}$. The tracking efficiency of different MPPT algorithms for the PV system is specified in Table-3. From the above results, it can be concluded that the suggested MIWO-P\&O technique has a good tracking competency with improved DC-link voltage control capability (i.e., lower peaks/dips) as compared to the PSO-P\&O [13] and GWO-P\&O [14] based hybrid MPPT techniques.

Table 3: Comparative voltage deviation and efficiency $\left(\eta_{M P P T}\right)$

\begin{tabular}{|l|c|c|c|}
\hline \multicolumn{1}{|c|}{ Performance indexes } & $\begin{array}{c}\text { Scheme } \\
{[\mathbf{1 3}]}\end{array}$ & $\begin{array}{c}\text { Scheme } \\
{[\mathbf{1 4 ]}}\end{array}$ & $\begin{array}{c}\text { Proposed } \\
\text { scheme }\end{array}$ \\
\hline Voltage deviation (Fig. 10(c)) & $1.12 \%$ & $0.825 \%$ & $0.525 \%$ \\
\hline PV efficiency (Fig. 10(d)) & $99.99 \%$ & $99.993 \%$ & $99.997 \%$ \\
\hline
\end{tabular}

\section{Case B:- Performance evaluation of MPPT under partial shading}

Partial shading is an unavoidable barrier that substantially affects the overall system performance resulting in multiple peaks with several local and one global peak (GP) as shown in Fig. 3(b). In order to present the accuracy (i.e., how close it takes the system to true global maximum power (GMP)) of the proposed MIWO-P\&O algorithm, the extraction of the actual PV output power during the PSC is illustrated in Fig. 11. In this case, the same partial shading pattern is illustrated which is considered in Table- 1 and Fig. 3(b). From $t=0.5 \mathrm{~s}$ to $3 \mathrm{~s}$, the solar irradiance of each PV module is $1000 \mathrm{~W} / \mathrm{m}^{2}$. Fig. 11 depicts that the MIWO-P\&O extricates a better dynamic response with higher power tracking efficiency $\left(\eta_{M P P T}\right)$ than some of the existing hybrid algorithms. The exact value of the $\eta_{M P P T}$ for different MPPT algorithms of the PV system is provided in Table-4. The same can be analyzed for other PSCs that the proposed MIWO-P\&O contributes higher $\eta_{M P P T}$ than PSO-P\&O [13] and GWO-P\&O [14].

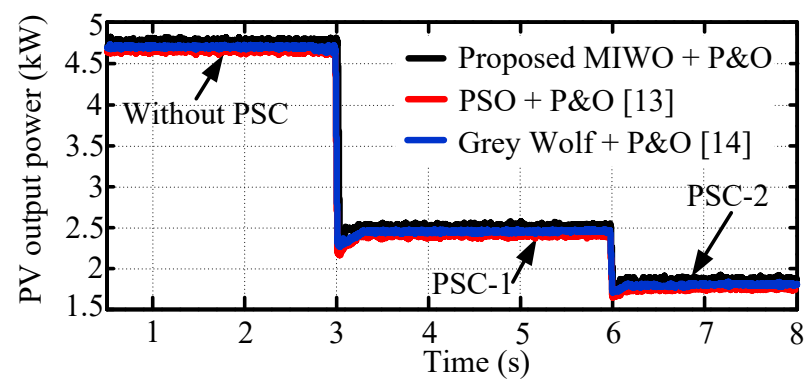

Fig. 11: PV output power under partial shading for one array

Table 4: Comparative voltage deviation and efficiency $\left(\eta_{M P P T}\right)$

\begin{tabular}{|c|c|c|c|}
\hline Performance index & $\begin{array}{c}\text { Scheme } \\
{[\mathbf{1 3}]}\end{array}$ & $\begin{array}{c}\text { Scheme } \\
{[\mathbf{1 4 ]}}\end{array}$ & $\begin{array}{c}\text { Proposed } \\
\text { scheme }\end{array}$ \\
\hline PV efficiency & $99.84 \%$ & $99.91 \%$ & $99.99 \%$ \\
\hline
\end{tabular}

\section{Case C:- Performance evaluation during variations of the atmospheric phenomena}

In this case study, a rapid change in solar insolation $\{$ (Fig. 12(a) $\}$ and temperature \{Fig. 12(b) $\}$ of the photovoltaic cell is considered to present the effectiveness of the proposed control strategy. The corresponding dynamic power response of different subsystems and the load power of the proposed controller are displayed in Fig. 12(c). Since the SoC of the BES restricted between $0.2-0.8$ (i.e., within the threshold limits), the electrolyzer and FC are non-operational (doesn't participate for power balancing) during this period as discussed in Section-3.1. Hence, the power deficiency between the generation and demand is well maintained by the battery system.
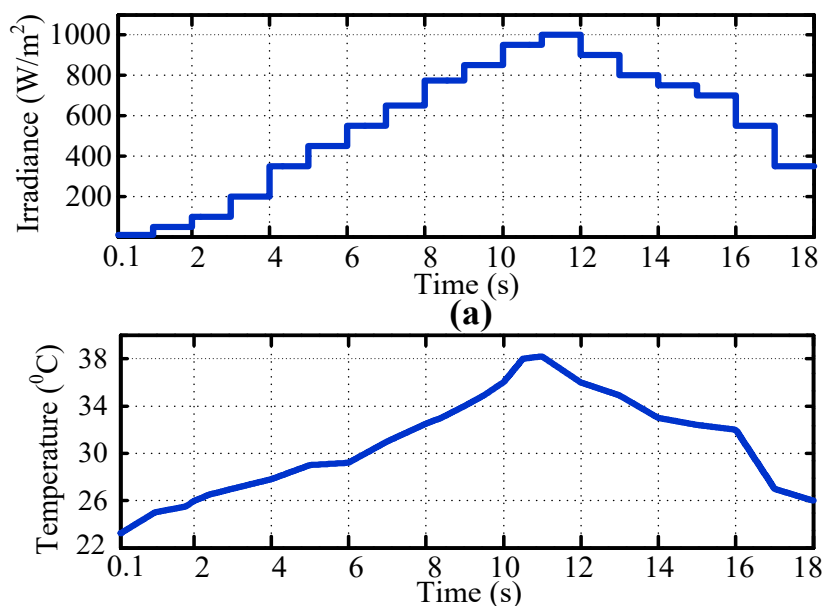

(b)

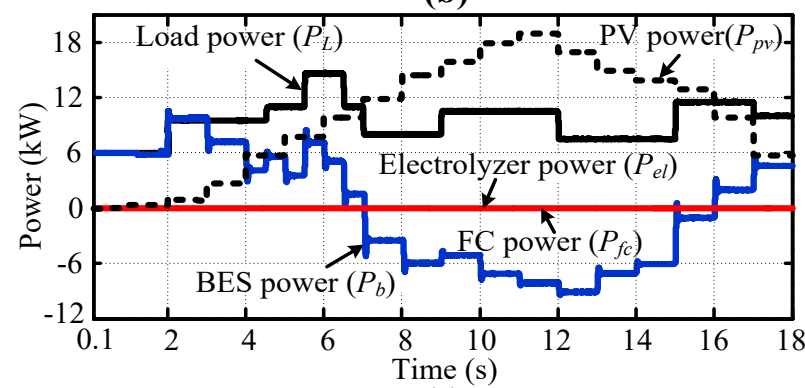

(c)

Fig. 12: (a). Variation in solar insolation, (b). Change in temperature, and (c). Dynamic power of the different subsystems

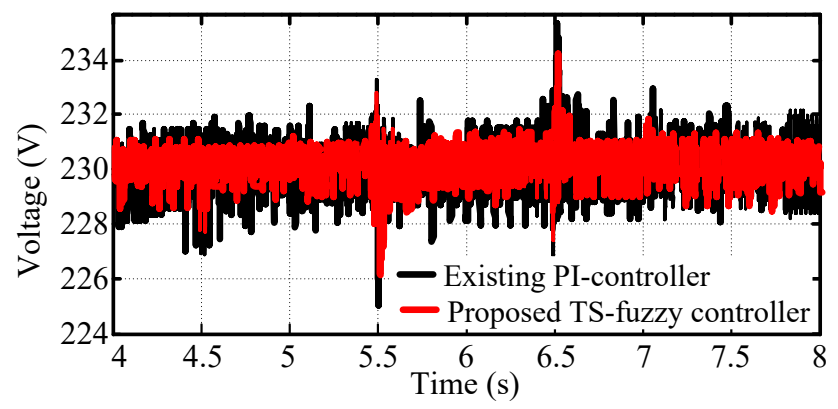

Fig. 13: Comparative RMS voltage at PCC for phase-A

Furthermore, the PCC voltage is regulated through the TSfuzzy based PWM switching topology for maintaining a stable and flexible power system operation. In Fig. 13, it can be seen that the TS-fuzzy based inverter control maintains the adequate quality voltage and less oscillatory in nature as compared to the conventional PI-control. From Fig. 13, it can be evaluated that the maximum percentage of the peak-to-peak RMS voltage deviation in the TS-fuzzy based controller and the PI-controller are $3.06 \%$ and $4.34 \%$, respectively. Moreover, the same observations have been noticed for Phase$B$ and Phase- $C$ at PCC. 
Case D:- Performance of battery and electrolyzer for the standalone system

In this example, the BES is fully charged (i.e., the $\mathrm{SoC}$ is 0.8 or above), as a result, the excess power is received by the dump load (i.e., electrolyzer). The power-sharing response graphs between each subsystem of the microgrid are shown in Fig. 14(a). After $t=2.48 \mathrm{~s}$, with the increase in battery SoC above 0.8 , the battery stops charging (i.e., thus BES power decreases to zero) and the electrolyzer (i.e., dump load) adopts/receives the excess/surplus power for power balancing of the proposed technique with the aim of maintaining the DClink voltage and PCC voltage at its nominal value. The corresponding SoC graph of the battery system is presented in Fig. 14(b).

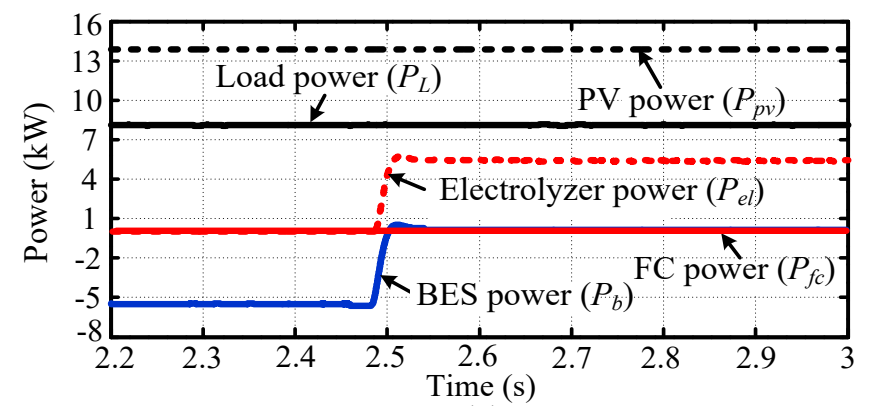

(a)

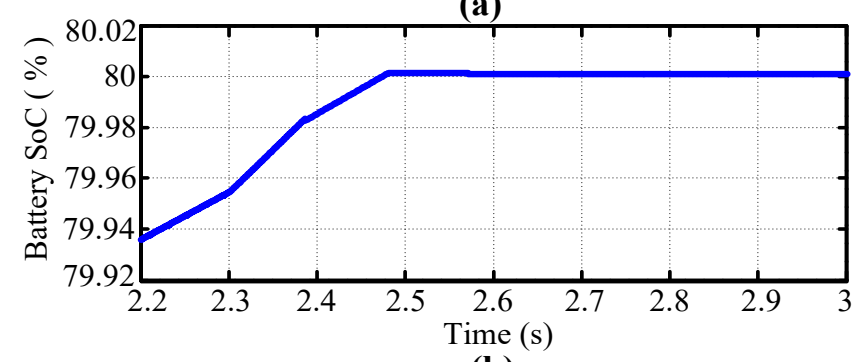

(b)

Fig. 14: (a). Power responses of different subsystems, and (b). SoC of the battery system

\section{Case E:- Performance of battery and FC for the standalone system}

In this case study, the power-sharing performance of the $\mathrm{FC}$ is presented which is allied through a Boost converter to the DC-bus of the DC-microgrid. In practice, the discharge capacity of the battery is three-times it's rating during rapid transient scenarios due to its electrochemical nature of the operation [23]. So, in order to meet the instantaneous power demand (i.e., load rises from $7.5 \mathrm{~kW}$ to $14.6 \mathrm{~kW}$ at $t=1.5 \mathrm{~s}$ ), BES delivers the required power instantly due to its highspeed retaliation as shown in Fig. 15(a). In this process, the $\mathrm{SoC}$ of the BES goes down to 0.2 at $t=2.8 \mathrm{~s}$. Since FC cannot act instantaneously due to its sluggish dynamic response, BES continuously supplies the power momentarily to meet power demand. So, the FC starts slowly feeding the power (i.e., power increases and the BES power decreases) to the system at $t=3 \mathrm{~s}$ and supplies the full required power approximately at $t=5.4 \mathrm{~s}$ as shown in Fig. 15 . On the other hand, BES power becomes zero (i.e., SoC of the BES drop down to 0.2) when the FC contributes the fully required power in steady-state.

From the above-mentioned investigation, it is established that FC's power slope is very less as compared to the slope of load power and BES can meet very high slope during transient scenarios. This kind of excellent symbiosis is attained by the intelligent coordination of the power management scheme as presented in Section-3. The corresponding RMS voltage responses of 3- $\Phi$ at the PCC are plotted in Fig. 15(b). Furthermore, Fig. 15(c) depicts the dynamics of DC-link voltage $\left(V_{d c}\right)$ operation is relatively stable in the proposed methodology than the PSO-P\&O [13] and GWO-P\&O [14].
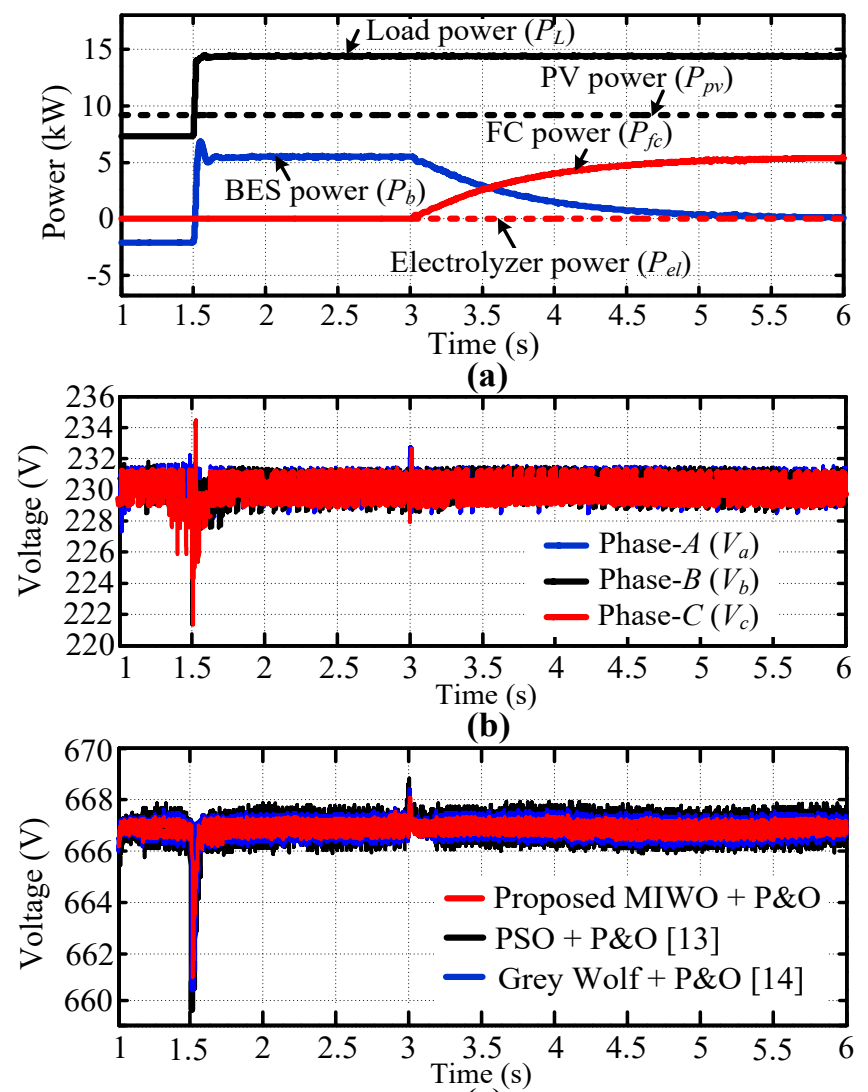

(c)

Fig. 15: (a). Power response of different subsystems, (b). RMS phase voltages at PCC, and (c). Comparative dynamic DC-link voltage response

\section{Case F:- Performance evaluation for unbalanced load}

With the purpose of presenting the effectiveness of the proposed PCC voltage compensation topology, the corresponding unbalanced RMS load currents of the three phases are: $I_{a}=31.819 \mathrm{~A}, I_{b}=9.192 \mathrm{~A}$ and $I_{c}=22.98 \mathrm{~A}$ are considered after $t=1.5 \mathrm{~s}$. The corresponding instantaneous $3-\Phi$ currents are shown in Fig. 16(a). In this case study, the solar insolation for each PV string is taken as $1000 \mathrm{~W} / \mathrm{m}^{2}$. For the specified unbalanced load currents, the instantaneous 3- $\Phi$ voltages at PCC are illustrated in Fig. 16(b). It is found that the PCC voltages are relatively balanced due to the generating distinct modulation indexes (MI) for each phase as shown in Fig. 16(c). The corresponding 3- $\Phi$ RMS voltages of each phase at PCC are given in Fig. 16(d). Moreover, the magnitude of the total harmonic distortion (THD) for the proposed TS-fuzzy controller and the existing PI-controller is $3.39 \%$ and $4.28 \%$, respectively. Due to page constraints, the THD in terms of the Fast Fourier Transform (FFT) graph of the inverter output voltage is not provided in this paper. From the data, it depicts that the harmonic content of the microgrid voltages is found well within the IEEE-519 standard limits 
and maintains the power quality (i.e., THD level lower than $5 \%)$ in the proposed controller $[17,33]$.

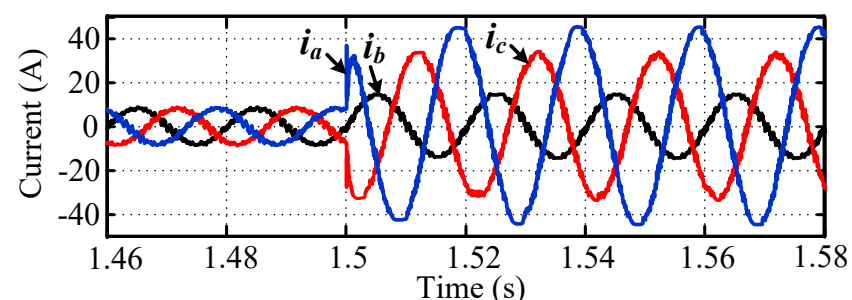

(a)

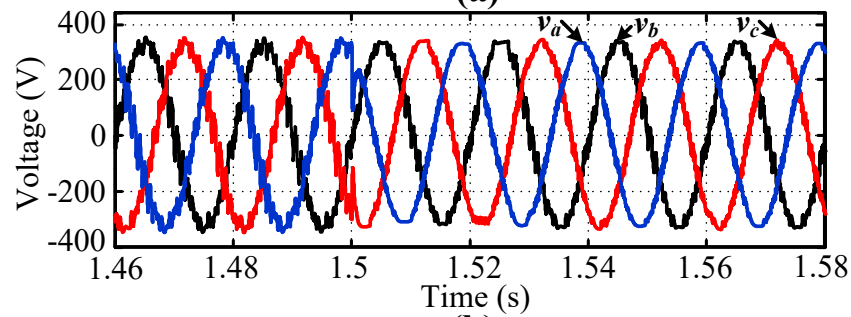

(b)

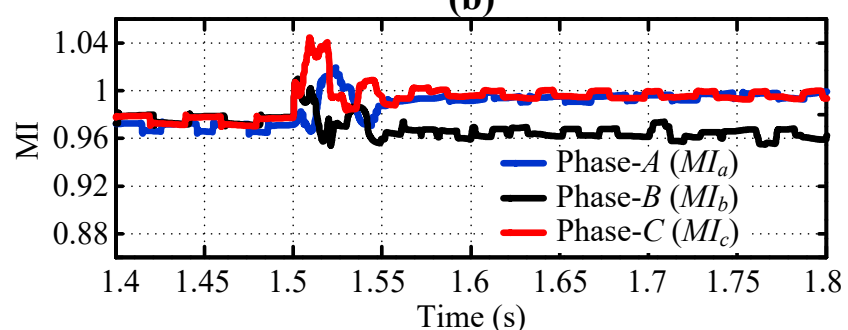

(c)

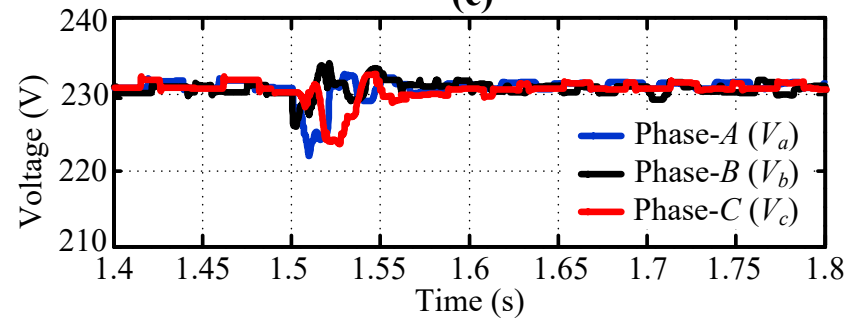

(d)

Fig. 16: Instantaneous system parameters: (a). Unbalanced phase load currents, (b). Balanced phase voltages, (c). Individual MI of each phase, and (d). RMS phase voltages at the PCC

\section{Case G:- Performance evaluation for single-phase to ground (LG)-fault scenario}

In this case study, a single-phase to ground ( $L G)$-fault scenario is considered to verify the effectiveness of the proposed control strategy. The $L G$-fault occurs at the time $(t)=1.5 \mathrm{~s}$ on Phase-A and the fault exists for $100 \mathrm{~ms}$ (i.e., 5cycles of the operating frequency) as shown in Fig. 17. The operating frequency of the microgrid is $50 \mathrm{~Hz}$ and the solar insolation for each PV string is taken as $1000 \mathrm{~W} / \mathrm{m} 2$. Fig. 17 illustrates that the dynamic responses of the DC-link voltage and the RMS voltage of Phase-A are improved in the proposed TS-fuzzy controller as compared to the existing PI-controller. The same observations have been noticed for the $L G$-fault in Phase-B and $\mathrm{C}$ and other types of fault scenarios of the microgrid. From the above studies, it can be concluded that the proposed controller contributes to an improved voltage stability profile for different power system events/contingencies. However, the dynamics (i.e., over/undershoot, settling time) of the voltage response depends on the nature of the system events/contingencies such as variations in solar irradiance/temperature and power mismatch between power generation and demand, fault, etc.

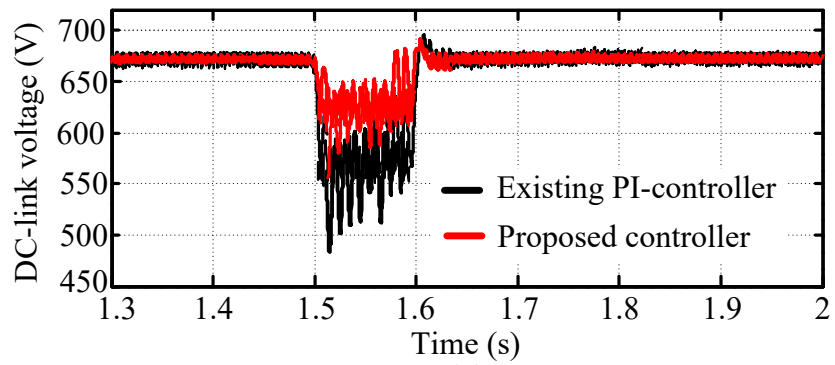

(a)

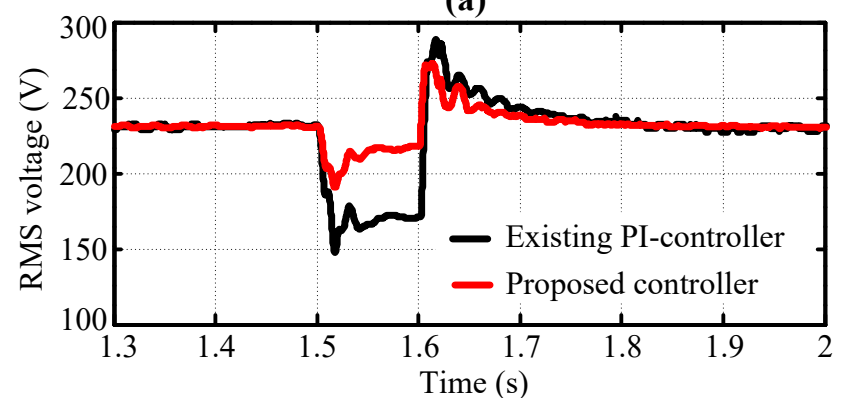

(b)

Fig. 17: Single-line to ground ( $L G)$-fault: (a). DC-link voltage response, and (b). RMS voltage of Phase-A

\section{CONCLUSION}

This paper has presented a MIWO assisted P\&O-based hybrid MPPT algorithm for harvesting the optimal power from a standalone PV system under both uniform solar irradiance and partially shaded conditions. From the comparative studies, it is found that the MIWO-P\&O technique exhibits superior performances such as the higher MPPT efficacy with faster convergence towards the global peak (GP) as compared to the PSO-P\&O and GWO-P\&O based hybrid-MPPT techniques. The salient feature of the proposed standalone microgrid is that no additional MPPT circuit is necessitated for the PV. The DC/DC converter (between the DC-bus and BES) not only regulates the DC-link voltage but also accomplishes the MPPT action. The proposed DC-voltage control and power management strategy attain effective control operation between the PV-battery-FC-electrolyzer-load of the microgrid during power system contingencies (e.g., PSCs and load variations). The proposed inverter control helps in maintaining a smoother balanced PCC voltage under both balanced and unbalanced load conditions. The OPA-LRT based real-time HIL simulation results exhibit that the performance of the proposed controller is satisfactory under steady-state as well as transient circumstances as per the microgrid standard limits.

\section{APPENDIX}

Value of the TS-fuzzy constants and PI-controller gains

\begin{tabular}{|l|l|l|}
\hline Converter/Inverter & \multicolumn{1}{|c|}{ TS-fuzzy controller } & \multicolumn{1}{c|}{ PI-controller } \\
\hline Battery converter & $a_{1}=3.7, a_{2}=2.1, a_{3}=-3.6$, & $K_{p 1}=1$, \\
& $a_{4}=2.8$ and $a_{5}=7.008$. & $K_{i 1}=85$ \\
\hline Fuel cell & $a_{1}=25.1, a_{2}=0.35, a_{3}=$ & $K_{p 2}=300$, \\
converter & $-5.5, a_{4}=2.8$ and $a_{5}=6.08$. & $K_{i 2}=50$ \\
\hline
\end{tabular}




\begin{tabular}{|l|l|l|}
\hline $\begin{array}{l}\text { Electrolyzer } \\
\text { converter }\end{array}$ & $\begin{array}{l}a_{1}=3.1, a_{2}=0.68, a_{3}=-8.9, \\
a_{4}=2.8 \text { and } a_{5}=60.007 .\end{array}$ & $K_{p 3}=4$, \\
\hline 3- $\Phi$ inverter & $K_{13}=187.77, a_{2}=0.285, a_{3}=$ & $K_{p 4}=1.6$, \\
& $-25.2, a_{4}=7$ and $a_{5}=17.7$. & $K_{i 4}=36$ \\
\hline
\end{tabular}

The design value of inductors $(L)$ and capacitors $(C)$

\begin{tabular}{|l|l|l|}
\hline \multicolumn{1}{|c|}{$\begin{array}{c}\text { DC/DC converter } \\
\text { (Fig. 1) }\end{array}$} & \multicolumn{1}{|c|}{$\begin{array}{c}\text { Inductance } \\
(\mathbf{m H})\end{array}$} & $\begin{array}{c}\text { Capacitance } \\
(\boldsymbol{\mu} \mathbf{F})\end{array}$ \\
\hline Buck-boost converter (Battery) & $L_{b}=5.54$ & $C_{b}=2500$ \\
\hline Boost converter (Fuel cell) & $L_{f}=5.513$ & $C_{f}=370$ \\
\hline Buck converter (Electrolyzer) & $L_{e}=0.813$ & $C_{e}=900$ \\
\hline$L C$-filter & $L_{f}=3.6$ & $C_{f}=6.85$ \\
\hline DC-link capacitor & - & $C_{d c}=4400$ \\
\hline
\end{tabular}

\section{REFERENCES}

[1] G. Li, Y. Jin, M. W. Akram, X. Chen, and J. Ji, "Application of Bioinspired Algorithms in Maximum Power Point Tracking for PV Systems under Partial Shading Conditions-A Review," Renewable and Sustainable Energy Reviews, vol. 81, no. 1, pp. 840-873, January 2018.

[2] X. Li, et al., "Comprehensive Studies on Operational Principles for Maximum Power Point Tracking in Photovoltaic Systems," IEEE Access, vol. 7, pp. 121407-121420, September 2019.

[3] A. Mohapatra, B. Nayak, P. Das, and K. B. Mohanty, "A Review on MPPT Techniques of PV System under Partial Shading Condition," Renew. and Sustain. Energy Reviews, vol. 80, pp. 854-867, Dec. 2017.

[4] S. Motahhir, A. El Hammoumi, A. El Ghziza, "The Most Used MPPT Algorithms: Review and the Suitable Low-cost Embedded Board for Each Algorithm", Journal of Cleaner Production, vol. 246, no. 1, pp. 117, February 2020.

[5] J. Ahmed, and Z. Salam, "A Modified P\&O Maximum Power Point Tracking Method with Reduced Steady State Oscillation and Improved Tracking Efficiency," IEEE Trans. on Sustainable Energy, vol. 7, no. 4, pp. 1506-1515, October 2016.

[6] F. Belhachat, and C. Larbes, "A Review of Global Maximum Power Point Tracking Techniques of Photovoltaic System under Partial Shading Conditions", Renewable and Sustainable Energy Reviews, vol. 92, pp. 513-553, September 2018.

[7] K. Ishaque, and Z. Salam, "A Deterministic Particle Swarm Optimization Maximum Power Point Tracker for Photovoltaic System under Partial Shading Condition," IEEE Trans. Industrial Electronics, vol. 60 , no. 8, pp. 3195-3207, August 2013.

[8] S. Titri, et al., "A New MPPT Controller Based on the Ant Colony Optimization Algorithm for Photovoltaic Systems under Partial Shading Conditions," Applied Soft Computing, vol. 58, pp. 465-79, Sep. 2017.

[9] Y. P. Huang, M. Y. Huang; and C. E. Ye, "A Fusion Firefly Algorithm with Simplified Propagation for Photovoltaic MPPT under Partial Shading Conditions," IEEE Trans. on Sustainable Energy, Early Access, pp. 1-1, January 2020

[10] C. Huang et al., "A Prediction Model Guided Jaya Algorithm for the PV System Maximum Power Point Tracking", IEEE Trans. on Sustainable Energy, vol. 9, no. 1, pp. 45-55, January 2018.

[11] A. K. Podder; N. K. Roy; and H. Roy Pota, "MPPT Methods for Solar PV Systems: A Critical Review Based on Tracking Nature," IET Renew. Power Generation, vol. 13, no. 10, pp. 1615-1632, July 2019.

[12] A. M. Eltamaly and H. M. H. Farh, "Dynamic Global Maximum Power Point Tracking of the PV Systems under Variant Partial Shading Using Hybrid GWO-FLC", Solar Energy, vol. 177, pp. 306-316, August 2019.

[13] K. Sundareswaran, V. Kumar, and S. Palani, "Application of a Combined Particle Swarm Optimization and Perturb and Observe Method for MPPT in PV Systems under Partial Shading Conditions," Renewable Energy, vol. 75, pp. 308-317, March 2015.

[14] S. Mohanty, B. Subudhi, and P. K. Ray, "A Grey Wolf Assisted Perturb \& Observe MPPT Algorithm for a Photovoltaic Power System", IEEE Trans. on Sustainable Energy, vol. 32, no. 1, pp. 340-347, March 2017.

[15] N. Kumar, I. Hussain, B. Singh, and B. K. Panigrahi, "Rapid MPPT for Uniformly and Partial Shaded PV System by Using Jaya DE algorithm in Highly Fluctuating Atmospheric Conditions", IEEE Trans. on Industrial Information, vol. 13, no. 5, pp. 2406-2416, October 2017.
[16] N. Priyadarshi, et al., "An Experimental Estimation of Hybrid ANFISPSO-Based MPPT for PV Grid Integration under Fluctuating Sun Irradiance," IEEE Systems Journal, vol. 14, no. 1, pp. 1218-1229, March 2020.

[17] F. Blaabjerg, Y. Yang, D. Yang, and X. Wang, "Distributed PowerGeneration Systems and Protection," Proceedings of the IEEE, vol. 105, no. 7, pp. 1311-1331, July 2017.

[18] J. Kumar, A. Agarwal, and V. Agarwal, "A Review on Overall Control of DC Microgrids," Journal of Energy Storage, vol. 21, pp. 113-138, February 2019.

[19] A. Gupta, S. Doolla, and K. Chatterjee, "Hybrid AC-DC Microgrid: Systematic Evaluation of Control Strategies," IEEE Trans. on Smart Grid, vol. 9, no. 4, pp. 3830-3843, July 2018.

[20] R. K. Sharma, and S. Mishra, "Dynamic Power Management and Control of a PV PEM Fuel-Cell-based Standalone AC/DC Microgrid Using Hybrid Energy Storage", IEEE Trans. on Industrial Applications, vol. 54, no. 1, pp. 526-538, February 2018.

[21] Y. Yang, Y. Qin, S. C. Tan, and R. Hui, "Efficient Improvement of Photovoltaic-Battery Systems in Standalone DC Microgrids Using A Local Hierarchical Control for the Battery System", IEEE Trans. on Power Electronics, vol. 34, no. 11, pp. 10796-10807, November 2019.

[22] M. Trifkovic, et al., "Modeling and Control of a Renewable Hybrid Energy System with Hydrogen Storage", IEEE Trans. on Control Systems Technology, vol. 22, no. 1, pp. 169-179, January 2014.

[23] S. G. Malla, and C. N. Bhende, "Voltage Control of Stand-alone Wind and Solar Energy System", Electrical Power and Energy Systems, vol. 56, pp. 361-373, March 2014.

[24] M. K. Senapati, C. Pradhan; S. R. Samantaray, and P. K. Nayak, "Improved Power Management Control Strategy for Renewable Energybased DC Micro-grid with Energy Storage Integration," IET Generation, Transmission \& Distribution, vol. 13, no. 6, pp. 838-849, May 2019.

[25] S. Azadeh, and M. Saad. "Simulation and Hardware Implementation of Incremental Conductance MPPT with Direct Control Method Using Cuk Converter," IEEE Trans. on Industrial Electronics, vol. 58, no. 4, pp. 1154-61, April 2011.

[26] R. A. Jackey, A Simple, Effective Lead-Acid Battery Modeling Process for Electrical System Component Selection, The MathWorks, Inc, 2007.

[27] M. Ceraolo, "New Dynamical Models of Lead-Acid Batteries," IEEE Trans. on Power Systems, vol. 11, no. 4, pp. 1184- 1190, Nov. 2000.

[28] M. A. Danandeh, and G. S. M. Mousavi, "Comparative and Comprehensive Review of Maximum Power Point Tracking Methods for PV Cells", Renewable and Sustainable Energy Reviews, vol. 82, no. 3, pp., 2743-2767, February 2018.

[29] L. Villa, et al., "A Power Electronics Equalizer Application for Partially Shaded Photovoltaic Modules", IEEE Trans. on Industrial Electronics, vol. 60, no. 3, pp. 1179-1190, March 2013.

[30] M. Misaghi, and M. Yaghoobi, "Improved Invasive Weed Optimization Algorithm (IWO) based on Chaos Theory for Optimal Design of PID Controller", Journal of Computational Design and Engineering, vol. 6 , no. 3, pp. 284-295, July 2019.

[31] T. Basso, "IEEE 1547 and 2030 Standards for Distributed Energy Resources Interconnection and Interoperability with the Electricity Grid," Tech. R

[32] C. Masetti, "Revision of European Standard EN 50160 on Power Quality: Reasons and Solutions, Proc. of $14^{\text {th }}$ International Conference on Harmonics and Quality of Power- ICHQP," Bergamo, Italy, pp. 1-7, September 2010.

[33] A. Anzalchi, and A. Sarwat, "Overview of Technical Specifications for Grid-connected Photovoltaic Systems," Energy Conversion and Management, vol. 152, pp. 312-327, November 2017.

[34] C. Pradhan, and C. N. Bhende, "Online Load Frequency Control in Wind Integrated Power Systems Using Modified Jaya Optimization," Engineering Applications of Artificial Intelligence, vol. 77, pp. 212-228, January 2019.

[35] C. Pradhan, C. N. Bhende, and A. K. Samanta, "Adaptive Virtual Inertia Based Frequency Regulation in Wind Integrated Power System," Renewable Energy, vol. 115, pp. 558-574, January 2018.

[36] J. Bélanger, P. Venne, and J. N. Paquin, "The What, Where and Why of Real-Time Simulation; Opal-RT Technologies Inc.: Montreal, QC, Canada” IEEE PES General Meeting, vol. 1, pp. 37-49, July 2010. 